\title{
Clinical Virology
}

National Cancer Institute

\section{Source}

National Cancer Institute. Clinical Virology. NCI Thesaurus. Code C18708.

A subdiscipline of virology focusing on aspects of human virology that directly pertains to virus-induced clinical conditions, including epidemiology, pathogenesis, diagnosis and detection, and prevention and treatment. 